\title{
THE EFFECT OF SOCIALISING PIGLETS DURING LACTATION ON PERFORMANCE, SUCKLING BEHAVIOUR AND WEANING AGGRESSION: A PRELIMINARY FIELD STUDY
}

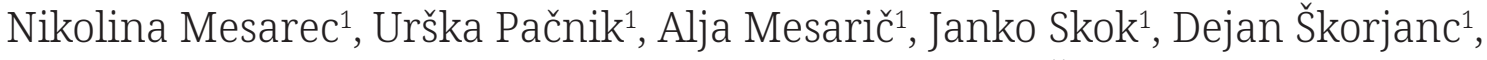 \\ Manja Zupan², Maja Prevolnik Povše ${ }^{1}$ \\ ${ }^{1}$ Faculty of Agriculture and Life Sciences, University of Maribor, Pivola 10, 2311 Hoče, Slovenia
${ }^{2}$ Biotechnical Faculty, Department of Animal Science, University of Ljubljana, Groblje 3, 1230 Domžale, Slovenia \\ Link to this article: https://doi.org/10.11118/actaun202068010073 \\ Received: 17. 9. 2019, Accepted: 5. 12. 2019
}

To cite this article: MESAREC NIKOLINA, PAČNIK URŠKA, MESARIČ ALJA, SKOK JANKO, ŠKORJANC DEJAN, ZUPAN MANJA, PREVOLNIK POVŠE MAJA. 2020. The Effect of Socialising Piglets During Lactation on Performance, Suckling Behaviour and Weaning Aggression: a Preliminary Field Study. Acta Universitatis Agriculturae et Silviculturae Mendelianae Brunensis, 68(1): 73-79.

\begin{abstract}
The post-weaning aggression among piglets is a serious problem in modern pig production which compromises animal welfare and health, as well as could cause considerable economic losses. To prevent post-weaning aggression between piglets an approach of early socialisation of piglets during lactation was tested in the present study. In the group farrowing pen (GFP) three individual farrowing pens were interconnected whereby piglets had free access to move across pens and/or cross-suckled alien sows that were still individually crated - passage between pens was released within $24 \mathrm{~h}$ postpartum. Piglets/litters in the control group went through the conventional breeding practice (i.e. individual farrowing pen/crate). Altogether, the experiment involved 235 piglets. The preliminary results revealed that the suckling order stability differed between studied breeding technologies (group and individual). About one third of all piglets (31.3\%) were found being involved (at least once) in the cross-suckling, i.e. suckling by the alien mother. Consequently, suckling stability was found generally lower in the GFP, with a significant drop after two weeks of lactation. Regarding the growth performance, piglets from GFP grew relatively, i.e. considering initial body weight, faster both during lactation and after weaning, although their daily weight gain was not significantly higher. The present preliminary study revealed early socialisation of piglets as an effective method to mitigate post-weaning aggression, as well as to improve their growth performance. However, considering mortality in lactation and disturbances in suckling stability, additional studies are needed to optimize the process of early socialisation, particularly in terms of piglets' age when grouping of non-littermates is implemented during lactation.
\end{abstract}

Keywords: pig, weaning, rearing technology, group farrowing pen, early socialisation, suckling behaviour, performance, aggression, animal welfare

\section{INTRODUCTION}

Animal welfare is one of the key premises in modern livestock production and depends mostly on the conditions in which the animals live. Many routine practices, as well as breeding conditions, do not satisfy natural needs, and thus do not enable the natural behaviour of the animals. The consequences often manifest as excessive aggression, decreased growth performance and health problems, which 
compromise animal welfare and lead to economic losses as well. In this context, weaning of piglets appear to be one of the most critical phases of pig breeding, since it is forced (arbitrary grouping) and sudden (mother-piglets separation, milkcreep feed transition), which differs considerably from the natural weaning process (Kaminski et al., 2005). Moreover, stocking density in the weaning groups is normally extremely high, whereby it is well known that with increasing group density the level of agonistic interactions is also increasing (Schmolke et al., 2004; Fu et al., 2016). Therefore, after weaning piglets are exposed to a completely different physical and social environment. Piglets are transferred to the new pen, suddenly deprived from mother's milk and fed with the feeding mixture (Weary et al., 2008). In addition, mixing of unfamiliar individuals leads to the establishment of the new dominance hierarchy (Messe and Ewbank, 1973). All these contribute to abnormal outbursts of aggressive behaviour in post-weaning groups, e.g. biting tails and ears, fighting, bullying and pushing between littermates and unfamiliar individuals (D'Eath, 2002). However, aggressive behaviour is naturally present in all mammals and is of vital importance for survival and appropriate development (Veenema, 2009), but it is important to prevent excessive aggression among piglets, which is a normal phenomenon in the commercial pig production.

A variety of measures to mitigate post-weaning stress and fights has already been tested and implemented by breeders in the previous years. Among the most common approaches are, for instance, the enrichment of pen with special toys (Scott et al., 2009) or/and with straw or strawlike material (Van the Weerd and Day, 2009; Zwicker et al., 2013). Furthermore, an innovative and simple approach was recently proposed by Mesarec et al. (2017), who managed to decrease weaning aggression using natural phenomena of imprinting. Another interesting possibility to mitigate post-weaning aggression is to socialise piglets during lactation (Weary et al., 1999; Morgan et al., 2014; Salazar et al., 2018). The socialisation during lactation (i.e. allowing spontaneous mixing of piglets from different litters) proved to be beneficial from the animal welfare and growth performance perspective. This approach was also tested in our experiment, however, in our experiment the contacts among piglets from different litters were enabled much earlier as compared to other studies (i.e. up to one day of age $v s$. more than a week of age).

The aim of the present study was to reduce the degree of aggression after weaning by socialising piglets during lactation period. The standard breeding practice, i.e. individual farrowing pen/ crate, was compared with an alternative, group farrowing pen, i.e. interconnected farrowing pens, whereby piglets had free access to move across pens and/or cross-suckled alien sows, which were still individually crated. To simulate natural condition, three litters were included in group farrowing pens. Namely, in the wild boar three females with their litters (and their subadult offspring) normally form a social group (Kaminski et al., 2005). Within the study, behaviour of piglets (suckling, aggression) and zootechnical parameters were analysed in lactation and post-weaning period in both breeding technologies.

\section{MATERIALS AND METHODS}

\section{Animals}

The experiment was carried out at the Pig Research Centre of the Faculty of Agriculture and Life Sciences under rearing conditions (field study) in the period from February 2017 to May 2018. During this period four repetitions of the experiment were carried out, thus considering various rearing conditions (summer/winter period, with/without outdoor access). In total, the experiment comprised 20 litter and 235 piglets (crossings between Large White and Slovenian Landrace).

\section{Experimental Design}

Two different breeding technologies were compared, i.e. individual or conventional (routinely used in Slovenia) and alternative group technology, which enables early socialisation of piglets. The experimental design is presented in Fig. 1.

\section{Individual Technology}

During lactation, two sows with their litters were housed in separate individual farrowing pens (where the piglets did not have the possibility of moving outside the pen). After the weaning, piglets of these two litters were grouped together into one weaning pen (i.e. Pen Ind), which represents a generally established breeding practice (conventional method of weaning).
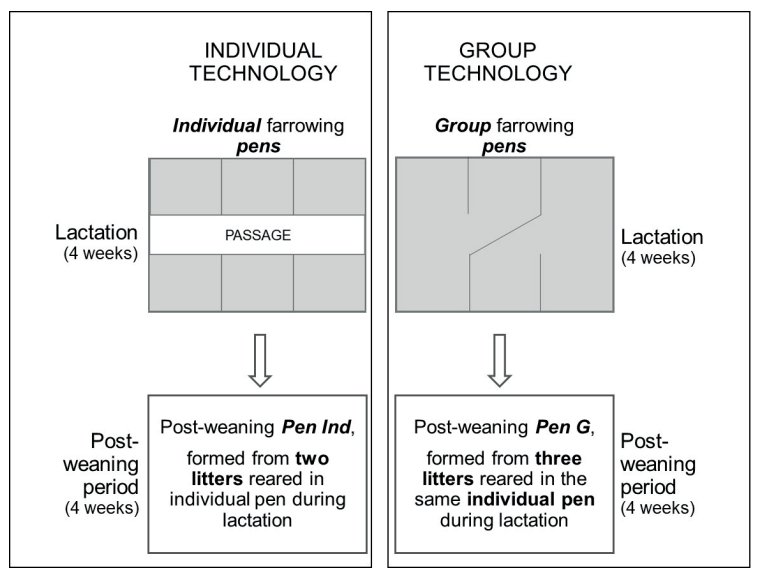

1: Experimental design 


\section{Group Technology}

During lactation three sows with their litters were housed in a group farrowing pen where piglets had free access to move across the three pens. As could be seen in Fig. 1, group farrowing pen was constructed simply by removing particular walls/ fences between individual pens (free passages among pens for piglets only). After the weaning, piglets of all three litters from the group farrowing pen were housed together into one weaning pen, i.e. Pen $G$ (alternative animal-friendlier method of weaning).

\section{Measurements and Observations}

In the first 24 hours after birth, piglets were individually marked on the back with a watersoluble chalk; different colours were used to distinguish different litters and combinations of lines to distinguish piglets within a litter. Additional identification with plastic ear tags was also used. The back marks were maintained throughout the experiment (the signs were restored at each observation). During lactation, growth performance, mortality, and suckling behaviour were analysed, and in the post-weaning period growth performance and aggression were analysed.

\section{Suckling Behaviour}

When studying suckling behaviour, observing individual piglets is essential. For this purpose, the method of direct observation was applied throughout the lactation. A total of seven observations were carried out covering all most important lactation phases (five in the first part of lactation when the suckling dynamics is the highest and two in the second part of lactation):

1. within the first 24 hours after birth,

2. in the middle of the $1^{\text {st }}$ week,

3. at the end of the $1^{\text {st }}$ week,

4. in the middle of the $2^{\text {nd }}$ week,

5. at the end of the $2^{\text {nd }}$ week of lactation,

6. at the end of $3^{\text {rd }}$ week and

7. at the end of $4^{\text {th }}$ week of lactation.

The individual observation involved at least two successive sucklings and lasts approximately three hours.

At each observation the data were gathered on mortality, suckling position of the piglets during the milk outflow (which happens between preand post-massage of the mammary gland and lasts about 10 to 15 seconds), lying position of the sow during the process of suckling (left or right side of lying), occurrence of cross-suckling piglets (C-S piglets) in the group farrowing pen (i.e. suckling in sow, which was not their biological mother), and litter identity for C-S piglets (the litter in which the piglet was located in a particular suckling).
Suckling order stability was calculated using the equation derived from the basic theory of probability:

P suck $=\frac{\left(\sum_{i=1 \text { toTP }} n i(n i-1)\right)}{N(N-1)}$,

where:

$n$..... was the number of sucklings on a particular teat pair by a certain piglet and

$N$.... was the total number of observed sucklings on a particular teat pair.

The $P$ value (suckling order stability) ranges from 0 to 1 , where 1 means complete stability (a particular teat pair was used by one piglet only) and 0 means complete instability (no piglet in the litter sucked more than once at a specified teat pair) (Skok and Škorjanc, 2013).

\section{Growth Performance}

Piglets were weighed two times during lactation (at birth and at weaning or day 1 and 28) and four times in the post-weaning period (days 35, 42, 49 and 56). Based on body weight and age daily weight gain was also calculated.

\section{Aggressive Behaviour}

Aggressive behaviour was monitored two days after weaning based on video analysis. Two types of interactions were studied: ear biting and pushing. During the period of observation, the type and frequency of interaction and identification of piglets - participants in interaction - were registered. Based on these data, a) the percentage of piglets that participated in interactions in individual and group technology were calculated and b) the rate of aggression was calculated as the ratio between the number of interactions of a specific piglet and the total number of interactions in a group.

\section{Statistical Analysis}

Statistical analysis was performed by using statistical package IBM SPSS Statistics version 25 for Windows (2005). Analysed parameters were compared between studied breeding technologies (group and individual technology) by applying $t$-test (numeric variables) or $\chi^{2}$ test (frequencies).

\section{RESULTS AND DISCUSSION}

\section{Cross-suckling}

In the group farrowing pens, about one third of all piglets (31.3\%) were at least once involved in the cross-suckling (Fig. 2a), i.e. suckling in sow, which was not their biological mother, about $4 \%$ of C-S piglets suckled at least once by each sow in the group pen (data not shown). Our results are in accordance with some previous studies on cross-suckling under rearing conditions (Olsen et al., 1998; Maletinska and 
Špinka, 2001), where about one third of all piglets was involved in cross-suckling too. On the opposite, Newberry and Wood-Gush (1985), recorded only one example of cross-suckling in semi-natural conditions (i.e. area of several hectares, low population density).

There are actually no studies on the time dynamics of cross-suckling in pigs. Our results (Fig. 2b) showed that the proportion of C-S piglets rapidly increased in the first week of lactation and stabilized at 15\% of C-S piglets in the second week. In the next two weeks, the proportion of C-S piglets fluctuated between 11 and 18\% (Fig. 1). Rising of the proportion of C-S piglets in the first week of lactation was in accordance with the proportion of new C-S piglets, i.e. piglets that practised cross-suckling for the first time in a given lactation period. Later, the proportion of new C-S piglets declined and slightly increased in the second half of lactation, which is probably due to higher needs of piglets who tried to obtain more sources (milk) to cover needs through additional cross-suckling.

As seen in Fig. 2a, the increase in the proportion of C-S piglets in group farrowing pens is relatively constant. The percentage of C-S piglets increased intensively by the middle of the second week, when over a quarter of all piglets (27\%) were involved in the cross-suckling, whereupon the end of the second week there was no major increase in percentage of C-S piglets. An increase for additional $10 \%$ of the percentage of C-S piglets occurred again in the third and fourth week of lactation (altogether 37\% C-S piglets).

\section{Suckling Order Stability}

The results from Fig. 3 showed that the suckling order stability (defined as the probability of successive sucklings at the same suckling position/ teat pair) differed between the studied breeding technologies (group and individual). The suckling behaviour in individual pens has been relatively well studied (Skok and Gerken, 2016). In the opposite, the understanding of the dynamics of suckling order formation is quite incomplete in group pens (Newberry and Wood-Gosh, 1985; Olsen et al., 1998; Maletinska and Špinka, 2001).

Our results showed (Fig. 3) a lower degree of suckling order stability in group pens as compared to individual pens, which could be ascribed to crosssuckling behaviour. However, in both breeding technologies, the formation of suckling order progressed with similar dynamics during the first two weeks of lactation, when the suckling stability is generally known to rise (e.g. see Skok and Gerken, 2016). In the second half of the lactation, suckling order stabilised in the individual technology, while in the group breeding it began to decline constantly, which is in line with the results shown in Fig. 2 ( $a$ and b), which showed an increase in the proportion of cross-suckling in the second week. The C-S piglets are therefore expected to reduce the suckling order stability and its maintenance.

\section{Zootechnical Parameters}

Durinzog lactation the average mortality was $13.3 \%$ and exceeded the normal lactation losses of piglets, which is estimated to be around $12 \%$ according to the Slovenian breeding program for pigs (Kovač et al., 2005). The increased level of mortality could be at least partially attributed to the problems with mycotoxins in the feed for sows, which was at the time of experiment a general problem in Slovenia. The comparison of the individual and group breeding technologies showed $2 \%$ higher mortality in group pens, but higher fluctuations in mortality rate in individual pens, where in the extreme case the mortality was 33\% (data not shown).

It is assumed that the mortality rate in the group pens is significantly affected by the time of release of the passages between the pens. The release of the passages in the first 24 hours after birth (which was used in our experiment) may not be the optimal
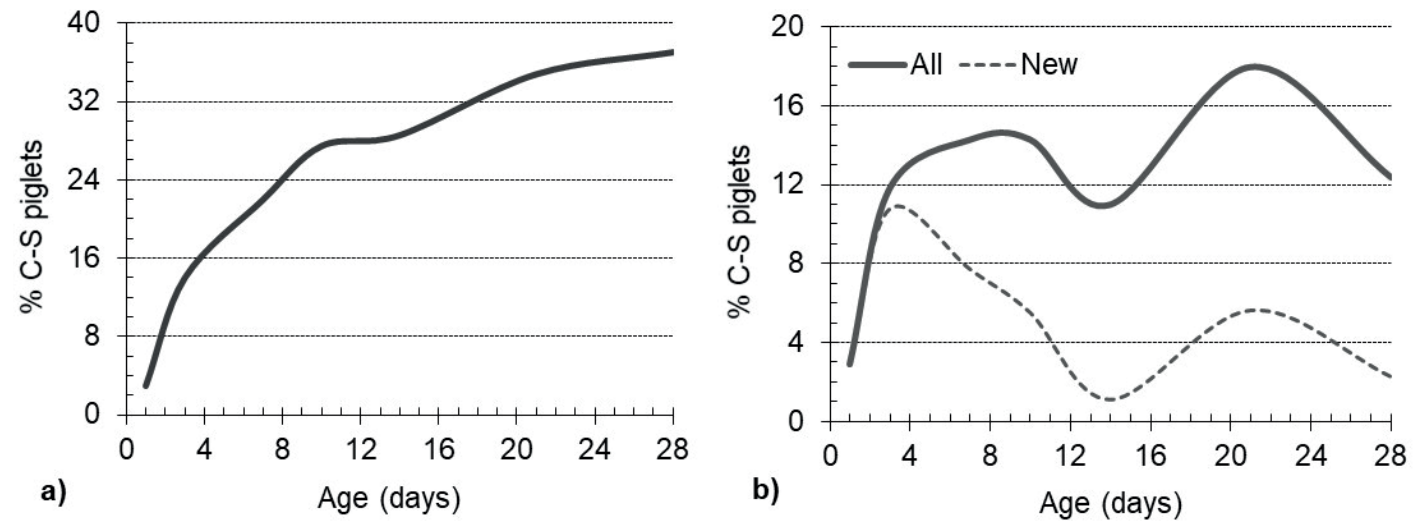

2: The cumulative curve of the percentage of C-S piglets ( $a$ ) and cross-suckling dynamics during lactation (b) C-S piglets - piglets which at least once successfully suckled in sow which is not their biological mother; All - all piglets that cross-suckled in a given observation point/period, New - piglets that appeared in crosssuckling for the first time in specific observation point/period 


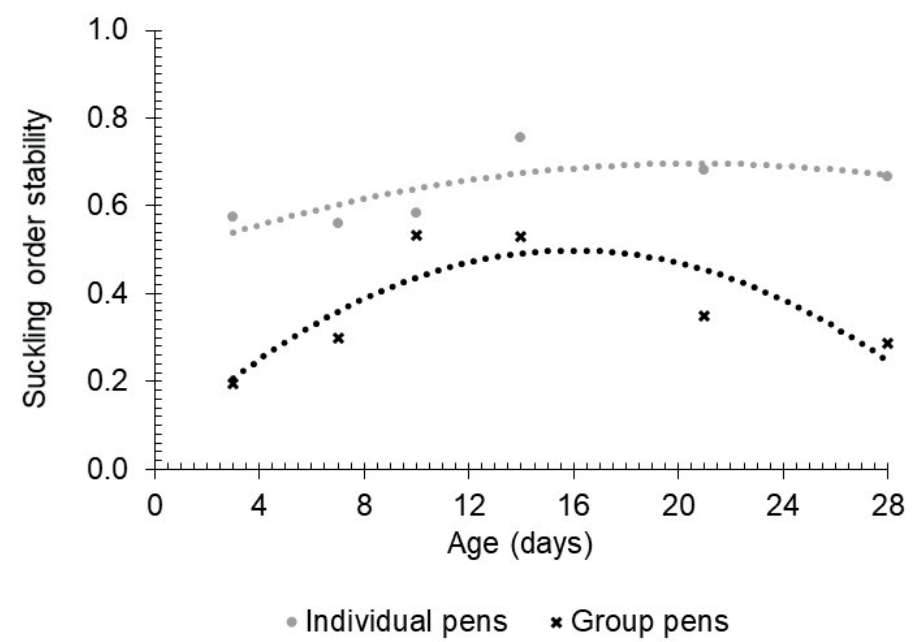

3: The trend of the suckling order stability during lactation in individual and group breeding technology

one - especially if we combine litters with higher age difference. Namely, in the first 48-72 hours after farrowing, the sow produces colostrum which is essential for the survival and development of piglets (Skok and Škorjanc, 2014). Thus, piglets may be deprived of colostrum if they have to compete with older/stronger littermates. Additional research is needed for the technology optimization.

Growth performance of piglets was observed from birth to approximately two months of age. According to Fig. 4, piglets from both technologies had the same body weight at the beginning of the experiment (at birth), but piglets from group technology grew faster both during lactation and after weaning. The difference in body weight was
$0.4 \mathrm{~kg}$ at weaning (not significant), and $1.2 \mathrm{~kg}$ four weeks after the weaning (statistically significant). Daily weight gain in both lactation and postweaning period was slightly higher in piglets from group technology, but not statistically significant (data not shown). According to published studies (D'Eath, 2005; Salazar et al., 2018) growth rates of socialised and non-socialised piglets are similar.

\section{Post-weaning Aggression Interactions}

Post-weaning aggressive behaviour was analysed from videos, which were recorded first two days after weaning. Focus was made on two most commonly observed aggressive interactions - ear biting and pushing among the piglets. Overall, the

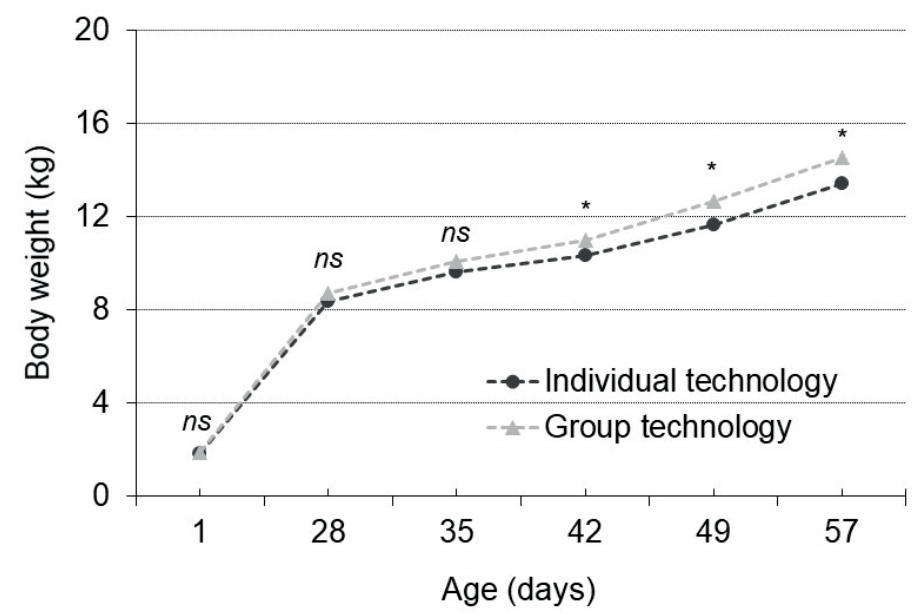

4: Body weight of piglets from individual and group technology from birth to app. months of age

Individual technology - individual farrowing pens during lactation and formation of post-weaning groups (Pen Ind) from two litters previously housed in individual farrowing pen

Group technology - group farrowing pens for three litters during lactation and formation of post-weaning groups (Pen $G$ ) from all three litters previously housed in group farrowing pen 
frequency of ear biting was three times higher than the frequency of pushing. In the selected observation period $72 \%$ of ear biting was observed in Pen Ind, while there was no difference between technologies as regards the frequency of pushing.

Further analysis of ear biting showed considerably higher percentage of piglets that participated in these interactions in the Pen Ind than in Pen G (85\% and 68\%, respectively; Fig. 5a). Our results additionally demonstrated significantly lower aggression rate in Pen $G$ as compared to Pen Ind (0.038 vs. 0.072, respectively). As expected, early socialisation resulted in less aggression after weaning, while a certain level of aggression was still present - probably due to the social hierarchy modification after environmental changes, but this is considered normal. Our results are in accordance with some other published studies which reported that socialised piglets have fought less after weaning (Weary et al., 1999; Morgan et al., 2014; Salazar et al., 2018). Ultimately, according to D'Eath (2005), early socialisation has long-term benefits for pig social behaviour.

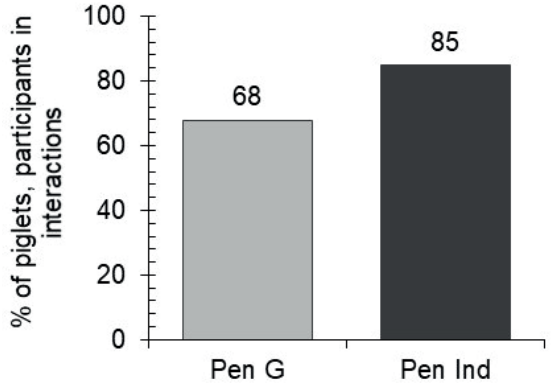

a)

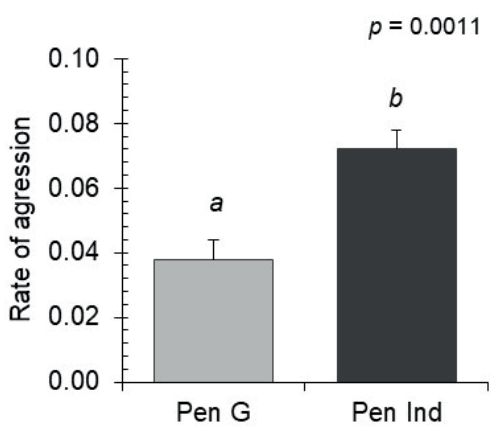

b)

5: Percentage of piglets participated in interactions of ear biting (a) the rate of aggression in individual and group technology (b)

Pen Ind - formation of post-weaning groups from two litters previously housed in individual farrowing pen, Pen $G$ - formation of post-weaning groups from all three litters previously housed in group farrowing pen

\section{CONCLUSION}

Group farrowing pens enabled early socialisation of piglets from different (three in our case) litters, including cross-suckling (which was performed by one third of all piglets). Cross-suckling caused disturbances in the formation of suckling order, but did not significantly affect growth during lactation. Socialised piglets showed significantly less post-weaning aggression and faster growth rate as compared with the piglets reared in individual farrowing pens. The present preliminary study revealed early socialisation of piglets as an effective method to mitigate post-weaning aggression, as well as to improve their growth performance. However, considering mortality in lactation and disturbances in suckling stability, additional studies are needed to optimize the process of early socialisation, particularly in terms of piglets’ age when grouping of non-littermates is implemented during lactation.

\section{Acknowledgements}

The research was founded by the Slovenian Research Agency and Ministry for Agriculture, Forestry and Food (project V4-1604).

\section{REFERENCES}

D’EATH, R. B. 2002. Individual aggressiveness measured in a resident- intruder test predicts the persistence of aggressive behaviour and weight gain of young pigs after mixing. Appl. Anim. Behav. Sci., 77(4): 267-283.

D’EATH, R. B. 2005. Socialising piglets before weaning improves social hierarchy formation when pigs are mixed post-weaning. App. Anim. Behav. Sci., 93(3-4): 199-211.

FU, L., LI, H., LIANG, T., ZHOU, B., CHU, Q., SCHINCKEL, A. P., YANG, X., ZHAO, R., LI, P. and HUANG, R. 2016. Stocking density affects welfare indicators of growing pigs of different group sizes after regrouping. Appl. Anim. Behav. Sci., 174: 42-50. 
KAMINSKI, G., BRANDT, S., BAUBET, E. and BAUDOIN, C. 2005. Life-history patterns in female wild boars (Sus scrofa): mother-daughter postweaning associations. Can. J. Zool., 83: 474-480.

KOVAČ, M. and MALOVRH, Š. 2012. Slovenian breeding program for pigs SloHibrid [in Slovenian: Rejski program za prašiče SloHibrid]. $1^{\text {st }}$ edition. Ljubljana: Kmetijsko gozdarska zbornica Slovenije.

MALETINSKÁ, J. and ŠPINKA, M. 2001. Cross-suckling and nursing synchronisation in group housed lactating sows. App. Anim. Behav. Sci., 75(1): 17-32.

MEESE, G. B. and EWBANK, R. 1973. The establishment and nature of the dominance hierarchy in the domesticated pig. Anim. Behav., 21(2): 326-334.

MESAREC, N., PREVOLNIK POVŠE, M., ŠKORJANC, D. and SKOK, J. 2017. Gangs of piglets: Welfare and growth of imprinted and guided weaners. Appl. Anim. Behav. Sci., 195: 44-49.

MORGAN, T., PLUSKE, J., MILLER, D., COLLINS, T., BARNES, A. L., WEMELSFELDER, F. and FLEMING, P. A. 2014. Socialising piglets in lactation positively affects their post-weaning behaviour. Appl. Anim. Behav. Sci., 158: 23-33.

NEWBERRY, R. C. and WOOD-GUSH, D. G. 1985. The suckling behaviour of domestic pigs in a seminatural environment. Behaviour, 95(1): 11-25.

OLSEN, A. N., DYBKJÆR, L. and VESTERGAARD, K. S. 1998. Cross-suckling and associated behaviour in piglets and sows. App. Anim. Behav. Sci., 61(1): 13-24.

SALAZAR, L. C., KO, H.-L., YANG, H.-L., LLONCH, L., MANTECA, X., CAMERLINK, I. and LLONCH, P. 2018. Early socialisation as a strategy to increase piglets' social skills in intensive farming conditions. Appl. Anim. Behav. Sci., 206: 25-31.

SCHMOLKE, S. A., LI, Y. Z. and GONVOU, H. W. 2004. Effects of group size on social behaviour following regrouping of growing-finishing pigs. Appl. Anim. Behav. Sci., 88(1-2): 27-38.

SCOTT, K., TYLOR, L., GILL, B. P. and EDWARDS, S. A. 2009. Influence of different types of environmental enrichment on the behaviour of finishing pigs in two different housing systems 3. Hanging toy versus rootable toy of same material. Appl. Anim. Behav. Sci., 116(2-4): 186-190.

SKOK, J. and GERKEN, M. 2016. Suckling strategies in the pig: The Göttingen minipig as a model. Livest. Sci., 184: 78-84.

SKOK, J. and ŠKORJANC, D. 2013. Formation of teat order and estimation of piglets' distribution along the mammary complex using mid-domain effect (MDE) model. Appl. Anim. Behav. Sci., 144(1-2): 39-45.

SKOK, J. and ŠKORJANC, D. 2014. Fighting during suckling: is it really an epiphenomenon? Ethology, 120(7): 627-632.

SPSS. 2005. SPSS student version 13.0. [CD ROM]. Thousand Oaks (CA): Sage Publications.

VAN DE WEERD, H. A. and DAY, J. E. L. 2009. A review of enviromental enrichment for pigs housed in intensive housing systems. Appl. Anim. Behav. Sci., 116(1): 1-20.

VEENEMA, A. H. 2009. Early life stress, the development of aggression and neurobiological correlates: What can we learn from animal models? Front. Neuroendocrin., 30(4): 497-518.

WEARY, D. M., JASPER, J. and HÖTZEL, M. J. 2008. Understanding weaning distress. Appl. Anim. Behav. Sci., 110(1-2): 24-41.

WEARY, D. M., PAJOR, E. A., BONENFANT, M., ROSS, S. K., FRASER, D. and KRAMER, D. L. 1999. Alternative housing for sows and litters: 2. Effects of a communal piglet area on pre- and postweaning behaviour and performance. Appl. Anim. Behav. Sci., 65(2): 123-135.

ZWICKER, B., GYGAX, L., WECHSLER, B. and WEBER, R. 2013. Short- and long-term effects of eight enrichment materials on the behaviour of finishing fed ad libitum or restrictively. Appl. Anim. Behav. Sci., 144(1-2): 31-38. 